\title{
COOPERATION OF HIGHER EDUCATION AND ACADEMIC SCIENCE IN TRAINING OF BIODIVERSITY CONSERVATION SPECIALISTS
}

(C) 2018

Vasilyeva Olga Yurievna, doctor of biological sciences, head of Ornamental Plants Introduction Laboratory; professor of Botany and Landscape Architecture Department

Central Siberian Botanical Garden of Siberian branch of Russian Academy of Sciences

(Novosibirsk, Russian Federation); Novosibirsk State Agrarian University (Novosibirsk, Russian Federation)

Novikova Tatyana Ivanovna, doctor of biological sciences, head of Biotechnology Laboratory; professor of Botany and Ecology Department

Central Siberian Botanical Garden of Siberian branch of Russian Academy of Sciences

(Novosibirsk, Russian Federation); Novosibirsk State Pedagogical University (Novosibirsk, Russian Federation)

Vorobyova Irina Gennadievna, doctor of biological sciences, head of Postgraduate Education Department Central Siberian Botanical Garden of Siberian branch of Russian Academy of Sciences

(Novosibirsk, Russian Federation)

Fomina Tatyana Ivanovna, candidate of biological sciences, senior researcher of Ornamental Plants Introduction Laboratory; associate professor of the Chair of the Design of Architectural Environment Central Siberian Botanical Garden of Siberian branch of Russian Academy of Sciences

(Novosibirsk, Russian Federation);

Novosibirsk State University of Architecture, Design and Arts (Novosibirsk, Russian Federation)

Buglova Lubov Victorovna, candidate of biological sciences,

senior researcher of Ornamental Plants Introduction Laboratory

Central Siberian Botanical Garden of Siberian branch of Russian Academy of Sciences

(Novosibirsk, Russian Federation)

Sarlaeva Inna Yanovna, junior researcher of Ornamental Plants Introduction Laboratory; lecturer of Botany and Landscape Architecture Department

Central Siberian Botanical Garden of Siberian branch of Russian Academy of Sciences

(Novosibirsk, Russian Federation); Novosibirsk State Agrarian University (Novosibirsk, Russian Federation)

Abstract. The paper considers the problem of bachelors, masters and graduate students training for work in the field of plant biodiversity $e x$-situ conservation (out of natural habitats), taking into account the modern strategy of biodiversity conservation accepted by the world scientific community. The long-term analysis of bachelors and graduate students training effectiveness was performed in Novosibirsk State Agricultural University, Novosibirsk State Pedagogical University, Novosibirsk State University of Architecture, Design and Arts. Some training materials of National Research Tomsk State University and experience of training of CSBG graduate students majoring in introduction of rare and useful plants were used. The authors show the leading role of the subject «Introduction of plants» for this major. The lack of valuable references on this course is noted. The authors justify the use of a complex of classical botanical techniques and modern ways of data analysis, including digital processing of images and parameters of plant objects in the educational process. Three main directions of experiments with introduced plants are characterized. The authors emphasize cooperation of higher education and academic science including students' internship in research laboratories and centers of collective use of RAS institutes. This makes the most essential contribution to the training of young scientists who want their major to be conservation of plant biodiversity by methods of introduction and biotechnology.

Keywords: higher school; professional education; training; bachelors; masters; graduate students; academic discipline; educational program; biodiversity conservation; plant introduction; biotechnology; educational literature; seasonal development; ontomorphogenesis; reproductive biology; teaching.

УДК 372

Статья поступила в редакцию 01.02.2018

\section{ОСОБЕННОСТИ ГЕНДЕРНОГО ВОСПИТАНИЯ ДЕТЕЙ ДОШКОЛЬНОГО ВОЗРАСТА}

(C) 2018

Евтушенко Ирина Николаевна, кандидат педагогических наук, доцент кафедры педагогики и психологии детства

Быстрай Елена Борисовна, доктор педагогических наук, профессор, заведующий кафедрой немецкого языка и методики обучения немецкому языку

Артёменко Борис Александрович, кандидат биологических наук, исполняющий обязанности заведующего кафедрой теории, методики и менеджмента дошкольного образования Южно-Уральский государственный гуманитарно-педагогический университет (2. Челябинск, Российская Федеращия)

Аннотащия. В статье акцентируется внимание на значимости гендерного воспитания детей дошкольного возраста, детерминированная изменениями социокультурного фона, смещением акцентов в ценностных ориентациях людей. Для дошкольного возраста характерно интенсивное физиологическое созревание организма и формирование психики. Кроме того, именно в дошкольном возрасте формируется личность ребёнка, создаётся потенциал для успешной дальнейшей жизнедеятельности. Большую роль в гендерном воспитании дошкольников играет социум и нормы общественного поведения, ценностные ориентиры, которые превалиру- 
ют в нём в данное время. В этой связи перед системой дошкольного образования встаёт задача усвоения ребёнком значимого для жизни в обществе социального опыта и принятие существующей системы ценностей. Посредником в общении дошкольника и социума является педагог дошкольной образовательной организации, который должен понимать, что анатомо-морфологические и физиологические особенности ребёнка дошкольного возраста образуют лишь первый уровень иерархической лестницы взросления и вхождения в социум. Большая роль в гендерной социализации дошкольников отводится родителям, так как в процессе наблюдения за поведением своих родителей у ребёнка формируются определённые поведенческие стереотипы феминно и маскулинно окрашенные. На гендерную социализацию дошкольников большое влияние оказывают сверстники.

Ключевые слова: гендер; гендерное воспитание; гендерная социализация; дошкольное воспитание; дети дошкольного возраста; феминность; маскулинность; поведенческие стереотипы; общество; социальная среда; образ «Я»; «Я»-концепция; полоролевая идентификация; гендерная идентичность.

Настоящий период развития общества детерминирован изменениями социокультурного фона, смещением акцентов в ценностных ориентациях людей. В центре психолого-педагогических исследований находится процесс формирования личности с её индивидуальными особенностями, то есть формирование самости человека вне зависимости от его половой принадлежности. В этой связи актуальной является проблема гендерного воспитания детей, так как высокая степень феминистической направленности женщин и наличие маскулинности у мужчин, к сожалению, не гарантируют гармоничное личностное развитие индивида.

Таким образом, очевидна необходимость включения гендерного аспекта во все области человеческой жизнедеятельности. Гендерный аспект должен учитываться в разработке политических доктрин, экономических стратегий, культурной жизни общества и развития современной системы образования. Именно последняя призвана закладывать базис для гендерного воспитания детей, начиная с дошкольного возраста. В настоящее время данная проблема рассматривается только лишь в физиологическом, медицинском, социальном и психологическом ракурсах. Не существует целостной модели гендерного воспитания дошкольников, а также полноценных рекомендаций по вопросам организации гендерного воспитания. Очевидно наличие традиционных ограничений личностного роста дошкольников в зависимости от их пола. Данный маркер является доминирующей чертой всего современного общества, для которого характерны следующие детерминанты:

- неярко выраженная поляризация социальных ролей женщины и мужчины;

- сближение культурных стереотипов феминности и маскулинности;

- изменение ролей в брачно-семейных отношениях, в частности, нивелируется статус мужчиныдобытчика, что приводит к смещению ценностных ориентаций;

- превалирование в системе образования, начиная с домашнего и кончая вузовским, процесса феминизации, что приводит к таким негативным последствиям, как возникновение трудностей при службе в армии, неспособности выполнения традиционной мужской работы, перекладывании ответственности за семью на женские плечи;

- отсутствие у современных женщин чувства терпимости, умения создавать эмоционально-позитивную атмосферу в коллективе и семье, умение рациональной организации домашнего быта.

Данные тенденции приводят к снижению уровня рождаемости, увеличению числа разводов и числа неполных семей, что негативным образом сказывается на экзистенции всего социума.

Проблема гендерного воспитания чрезвычайно актуальна для детей дошкольного возраста, так как данный период детерминирован интенсивным физиологическим созреванием организма и формированием психики. Для детей данного возраста характерны бурные процессы взросления, проявляющиеся в увеличении мышечной массы и изменении костного скелета; с другой стороны, у детей дошкольного возраста развиваются все психические процессы: воображение, восприятие, мышление, память, речевые механизмы. Для них характерны гипервпечатлительность, эмоциональность, имитативные умения. Большая пластичность нервной системы является базисом для эффективного воспитания и обучения дошкольников.

Следует учитывать и тот факт, что именно в дошкольном возрасте формируется личность ребёнка, создаётся потенциал для успешной дальнейшей жизнедеятельности. Необходимо заложить фундамент для развития таких важных качеств личности, как нравственность, доброта, порядочность, уважение, толерантность к проявлениям иного образа мышления и жизни. Вслед за Д.И. Фельдштейном мы полагаем, что процесс присвоения ребёнком социальных норм является процессом единства и борьбы противоположностей. С одной стороны, социализация позволяет ребёнку принять нормы человеческого сосуществования, а с другой стороны, процесс социализации каждого отдельного ребёнка носит ярко выраженный индивидуальных характер [1, с. 46-48].

Нормы общественного поведения, ценностные ориентиры, существующие в обществе, установки и представления становятся внутренним содержанием личности дошкольника; у него складывается определённая модель мироздания, система обобщённых образов, таких как образ Родины, образ счастья, нравственные образы и др. В эпоху глобализационных процессов во всех сферах человеческой жизнедеятельности, перед лицом глобальных угроз особую значимость приобретает воспитание у дошкольников чувства любви к природе родного края и России в целом. Так, в ракурсе гендерной социализации воспитатели во время общения дошкольников старшего возраста с природой организуют рекультивацию традиционных для региона представителей флоры, при этом на плечи мальчиков ложится более тяжелая работа, девочки выполняют вспомогательные функции [2, с. $75 ; 3$, с. $106-108 ; 4$, с. $152 ; 5$, с. 82-85]. Целью воспитания ребёнка дошкольного возраста является усвоение им значимого для жизни в обществе социального опыта и принятие существующей системы 
Евтушенко И.Н., Быстрай Е.Б., Артёменко Б.А.

ценностей, что даёт ему возможность коммуницировать с другими представителями социума, осознавая самоценность и уникальность своего культурного и гендерного «Я».

Обратимся к ретроспективному анализу понятия «гендер», которое вошло в научный обиход благодаря американскому психологу и сексологу, занимавшемуся проблемами сексуальной идентичности, Джону Уильяму Мани. Им были введены в науку такие понятия, как «гендерная роль», «гендерная идентичность» и др. Разработанная им «карта любви» (Lovemap) характеризует сексуальные предпочтения индивидуума, формируемые в возрасте 5-8 лет.

Слово «гендер» в английском языке в своём первоначальном значении является грамматической категорией рода в силу того, что в нём отсутствует категория рода для неодушевлённых предметов. Данное слово относят к одушевлённым существам в случае необходимости уточнения пола. В отличие от медицинского слова «sex», обозначающего чисто физиологическую разность между полами, «gender» предполагает социальные и другие различия. Неслучайно Дж. В. Скотт определяет данную категорию как элемент социальных отношений, основанный на осознанных различиях между полами.

В зарубежной психологии в настоящее время культивируются четыре значения понятия «гендер», два из которых являются полярными; в рамках первого понятия «гендер» понимается как кардинально различное по отношению к естественному полу, второе же понятие, напротив, идентифицирует его с понятием пола. Третья трактовка данного понятия близка авторам статьи, так как она расширяет его в аспекте биологических и социальных проявлений пола. Мы не согласны с точкой зрения, в рамках которой «гендер» является символом неравенства полов, их иерархической организации (доминантный мужской и подчиненный женский).

Гендер, на наш взгляд, является смоделированной обществом и поддерживаемой социальными институтами системой ценностей, норм и характеристик мужского и женского поведения, стиля жизни, способа мышления, ролей и отношений мужчин и женщин, приобретенных ими в процессе социализации. Социальный пол (гендер) - не тождествен биологическому полу, так как он конструируется самой социальной практикой и социальными стереотипами, доминирующими в настоящее время в определённом социуме.

В отличие от нашей точки зрения, сегодня в Европе ведётся полемика по поводу понятия гендера и его сущностных характеристик. Так, с 2012 года в детских садах Швеции появилось местоимение «оно». Приверженцы данной точки зрения придумали искусственное местоимение «hen». Эквивалентом местоимения «он» в шведском языке является «han», а местоимения «она» - «hon». Импульсы для так называемого реформаторства дошкольного образования исходят от американской феминистки, автора теории гендерной перформативности - Джудит Батлер. Согласно ей, пол, гендер и сексуальность в реальном мире кажутся вещами глубоко взаимосвязанными в первую очередь из-за того, что общество навязывает формирование этой связи повторением особых формализованных действий. Действия эти - обязательно регулярные и постоянные - и формируют фактический пол человека. Она утверждает, что в современном мире не существует добровольности в формировании пола или сексуальности, а ключевую роль в определении пола играет давление извне. Автор призывает к тому, чтобы дети сами определяли свой пол [6, с. 58-62]. Идея гендерного равенства получила своё развитие в Швеции, где в 1998 году был принят закон «О противодействии гендерным стереотипам у детей». Согласно другому шведскому закону «О дискриминации» педагоги детских садов обязаны ежегодно проходить курсы повышения квалификации в области равноправия. По инициативе Дж. Батлер в 2010 году здесь организовали первый экспериментальный детский сад «Эгалиа» (в переводе «Равенство»). В «Эгалиа» запрещено произносить слова «мальчик» и «девочка», всех детей называют «hen». Шведское издательство «Саголикт Букфёрлагет» организовало поставку в «Эгалиа» соответствующих наглядных пособий. В частности, в данный детский сад поставили серию книг о мальчике Калле, который носил розовое платье в горошек, сказки про двух жирафов мужского пола, усыновивших крокодильчика и сказочку про принцессу, которая не любила принцев, но влюбилась в бедную девушку. В середине 2012 года в Швеции развернулась «hen»дискуссия, в рамках которой многие политики, педагоги, социологи, психологи конфронтировали с точкой зрения Дж. Батлер.

В соседней Норвегии депутат парламента Сольвейг Хорне открыто осудила теории гендерной перформативности, заявив, что она надеется никогда не увидеть ничего подобного в детских садах Норвегии. В сентябре 2012 года редакция шведской газеты «Дагенс Нюхетер» наложила запрет на использование слова «hen» на своих страницах, так как читатели начали выказывать по этому поводу своё недовольство.

Но, к сожалению, идеи Дж. Батлер являются актуальными для некоторых стран Евросоюза. Так, 4 февраля 2014 года в Европарламенте была принята резолюция по правам нового пола. Создание «третьего пола» предусматривает две подкатегории транссексуальные и интерсексуальные люди, у которых есть права мужчин и женщин. К первым относятся люди, сменившие пол хирургическим путём; вторые - имеют врожденные половые признаки мужчины или женщины. Данная резолюция позволяет принять «Дорожную карту Евросоюза против гомофобии и дискриминации по признаку сексуальной ориентации и половой идентичности», а такие страны, как, например, Болгария, - не принявшие ещё однополые «браки», будут «поощряться» обмениваться «хорошими практиками с государствами», где эти браки стали фактом.

В Германии же проявления феминизма имеют другой характер. В частности, во всех общественных институтах и организациях приняты такие клише делового этикета в обращении к коллективам обучающихся и работающих, как «Liebe Kolleginnen und Kollegen», «Liebe Studentinnen und Studenten», при этом суффикс «іn» показывает принадлежность к женскому полу.

Мы полагаем, что вышеназванные проявления феминизма в Европе могут пагубно повлиять на её 
эволюционирование. Авторы настоящей статьи придерживаются мнения психоаналитика и социолога Эриха Фромма, согласно которому человек, обретший идентичность, характеризуется чёткостью представлений о себе, верностью себе, что является основой для признания его людьми. В случае несформированной идентичности человек испытывает тревогу, неуверенность, враждебность, для него характерна «путаница ролей». Центральной проблемой воспитания личности является проблема становления своего «Я», формирования «Я»-концепции, которая включает в себя систему представлений о самом себе, своей половой роли и отношении к себе в виде самооценки [7, с. 36; 8, с. 205].

Что касается взглядов отечественных учёных на проблему гендера, то Е.Н. Каменская под «гендером» понимает систему социокультурных половых отношений, возникающих у мужчин и женщин в результате их общения между собой и с внешним миром и проявляющихся во всех сферах жизни человека и общества. Она определяет гендерное воспитание как процесс культурной, гендерной ориентации, идентификации и овладения подрастающим поколением нравственной культурой в сфере взаимоотношения полов в определённой культурной педагогически организованной среде [1, с. 16].

И.С. Кон, идентифицирует понятие «гендер» с социальным полом, социально детерминированными ролями, идентичностью и сферами деятельности мужчины и женщины, зависящими не от биологических половых различий, а от социальной организации общества [9, с. 56-58].

Мы понимаем под «гендером» социальный пол человека, формируемый в процессе воспитания личности и конгломирирующий в себе психологические, социальные и культурные отличия между мужчинами и женщинами; отношения между ними будем называть гендерными.

Значимость гендерного воспитания трудно переоценить, поскольку заложенный в дошкольном возрасте социально-гендерный багаж будет сопровождать индивида в течение всей его жизни.

Таким образом, воспитательной доминантой в процессе личностного становления мальчиков и девочек дошкольного возраста является не формирование жёстких установок маскулинности и феминности, а анализ партнёрских взаимоотношений между детьми разного пола, воспитание в русле общечеловеческих ценностей, взаимоуважения, толерантности, а также развитие поведенческо-гендерного репертуара детей в процессе их общения. Гендерное воспитание можно трактовать как процесс культурной гендерной ориентации, идентификации и овладения подрастающим поколением нравственной культурой в сфере взаимоотношений полов в определенной культурной среде.

Организуя педагогический процесс в рассматриваемом контексте, педагог дошкольной образовательной организации должен понимать, что анатомоморфологические и физиологические особенности являются лишь предпосылками для развития различий психологического характера между мальчиками и девочками, которые подвержены влиянию социаль- ных факторов (общественная среда, СМИ, ценностные установки, традиции данного общества и т.д.).

Ю.Е. Гусева считает, что гендерное воспитание имеет две стороны: в рамках процесса усвоения социального опыта ребёнок, начиная с дошкольного возраста, понимает, что значит быть мальчиком или девочкой; в рамках опредмечивания, т.е. процесса воспроизведения социального опыта, дошкольники реализуют в процессе общения усвоенные ими поведенческо-гендерные образцы [10, с. 154-155].

К концу раннего возраста ребёнок усваивает свою принадлежность, но ещё не знает, каким содержанием должны быть наполнены слова «мальчик», «девочка». Роль взрослых заключается в том, чтобы сформировать поведение ребёнка в гендерном аспекте в соответствии с принятыми в обществе установками и стереотипами, а также его осознание, что значит быть мальчиком или девочкой. В этой связи велико значение педагогов в гендерной социализации дошкольника. Они должны правильно формировать мировоззрение детей, распределять обязанности между мальчиками и девочками, осуществляя контроль и предоставляя помощь в их реализации [11, c. $122 ; 12$, с. 34$]$.

Высока роль в гендерной социализации детей дошкольного возраста родителей, так как именно родители образуют первичную социальную среду, через призму которой ребёнок общается с окружающим его миром. В процессе наблюдения за поведением своих родителей у ребёнка формируются определённые поведенческие стереотипы феминно и маскулинно окрашенные. Дошкольник подражает родителям как в манере одеваться, так и в манере поведения. Например, маленькие девочки любят примерять мамины туфли, бусы и другие аксессуары. Следует отметить тот факт, что неблагополучная социальная среда негативным образом сказывается на гендерной социализации дошкольника. Под социальной средой мы понимаем как ближайшее семейное окружение, так и круг сверстников, в который дети погружаются во дворе. Процесс гендерной социализации имеет и ярко выраженный личностный аспект. В частности, формирование стереотипов зависит от общего интеллектуального развития ребёнка и связано с проявлением самокатегоризации и интеграции собственного поведенческого опыта в своём образе «Я».

Большую роль в гендерной социализации дошкольников играет общество сверстников. Дети дошкольного возраста приходят в детский сад с определёнными, сложившимися в семье поведенческими стереотипами. Общаясь друг с другом, они закрепляют свою гендерную идентичность, которая позволяет им более жёстко выражать своё отношение к признакам маскулинности и феминности. Причём сверстники влияют на поведение мальчиков сильнее, чем на поведение девочек. Влияние оценки сверстников на поведение дошкольников бывает настолько сильным, что дети выбирают игрушки, соответствующие стереотипам игр мальчиков и девочек, хотя в одиночестве могут пользоваться любыми игрушками.

Очень часто поведенческие стереотипы детерминированы традиционными социальными установка- 
ми взрослых, через призму которых дети дошкольного возраста оценивают поведение своих сверстников, в результате чего они в некоторых случаях могут относиться к ним с недоверием. Согласно исследованиям Э. Маккоби [13-15], мальчики и девочки в большей степени подражают поведению первых.

В силу того, что в системе дошкольного образования доминирующее большинство сотрудников составляют представительницы женского пола, у мальчиков затормаживается процесс формирования маскулинности, который выражается в двух крайне диссонирующих поведенческих образцах: либо в полоролевой растерянности, либо в утрированно выраженной маскулинной ориентации, часто выраженной в агрессивном поведении по отношению к девочкам.

Процесс становления «Я»-концепции девочки часто может быть осложнён тем фактом, что некоторые из них, обладая ярко выраженными лидерскими качествами и высокими социальными способностями, не могут в полной мере реализовать их в процессе межличностного общения со сверстниками.

Несмотря на вышеперечисленные сложности, возникающие в процессе гендерной социализации дошкольников, мы придерживаемся мнения, что первые семь лет жизни являются сензитивным периодом, в рамках которого закладываются базисные структуры психики ребёнка, детерминирующие его развитие и социальное поведение в последующие периоды жизни. При этом следует учитывать тот факт, что не нужно говорить о половой идентичности раньше, чем у ребёнка формируется образ «Я», соответствующий возрасту трёх лет. В психологии выделяют три периода половой идентичности у детей дошкольного возраста. Первый период связан с физиологическими различиями у детей разного пола. Второй - с формированием так называемого номинативного пола. Полоролевая идентификация совпадает с возрастом 5-6 лет (третий период). В этой связи наиболее эффективным в плане гендерной социализации является возраст до 5-6 лет, так как управление данным процессом осуществляется наиболее лёгким путём.

Процесс формирования гендерной идентичности имеет два плана: внешний и внутренний. Первый, экстериоризируется посредством таких внешних атрибутов, как стиль одежды, манера поведения, выражающаяся в маскулинной женственности, либо феминной маскулинности, при этом социум демонстрирует большую степень толерантности к проявлениям первой. Второй аспект представляется нам более серьёзным, так как речь идёт о принципиальных различиях в стереотипах мужественности и женственности.

На основе компонентного состава социальной установки, то есть отношения личности к самой себе, включающей в себя, познавательный аспект (знание себя), эмоциональный (оценка своих качеств), поведенческий (практическое отношение к себе), Н.К. Радина конкретизирует содержание каждого из компонентов, а именно: она включает в первый компонент познание своего сходства и различий с представителями своего и противоположного пола (типизация и индивидуализация своего «Я». Второй компонент включает в себя эмоциональную оценку себя как представителя определенного пола. Третий компо- нент выражается в самоутверждении самого «Я» в общении и деятельности [16, с. 58-59].

Корреспондируясь с вышеназванными точками зрения, О.В. Рябов представляет гендерную идентичность в виде системы, включающей следующие взаимосвязанные, взаимодополняющие, взаимодействующие между собой компоненты:

- когнитивный - представление о своём соответствии или несоответствии той или иной модели маскулинности или феминности;

- эмоциональный - переживание подобного соответствия или несоответствия гендерным нормам;

- волевой - готовность к активным действиям в плане создания модели собственного гендерного поведения [17, с. 14].

Экстраполируя данную систему в плоскость гендерной социализации детей дошкольного возраста, T.А. Репина выделяет три этапа гендерного развития в дошкольном возрасте: 1 этап - осуществление гендерной идентификации (ребенок учится различать мужчину и женщину, девочку и мальчика и знать, какого рода поведение характеризует каждого из них, причисляет себя к мужскому или женскому полу, к мальчикам или девочкам); 2 этап - формирование гендерных предпочтений в различных сферах деятельности и жизни (этот этап связан с первым, так как для того, чтобы возникли первые гендерные предпочтения, ребенок должен знать, в чем заключаются различия в поведении людей разного пола); 3 этап - овладение поведением в соответствии с полоролевыми стандартами и формирование некоторых психических половых способностей (второй и третий этапы могут сосуществовать вместе) [18, с. 18-20; 19 , с. 35-36].

Рассмотрев в данной статье влияние семьи, сверстников, социума на процесс гендерной социализации детей, мы не можем не учитывать влияние целых культур на него. В частности, Герт Хофстеде делит все культуры на маскулинные и феминные. В первых доминируют такие ценности, как настойчивость, сила, независимость, материальный успех. К числу таких культур автор относит Австрию, Великобританию, Венесуэлу, Германию, Ирландию, Италию, Швейцарию, Японию. В феминных культурах ценятся больше всего эмоциональные связи между людьми, забота о других членах общества. Для них характерно социальное равенство полов, сочувствие неудачникам. Конфликты в них обычно решаются путём переговоров и достижения компромисса. К феминным культурам учёный относит Данию, Нидерланды, Норвегию, Португалию, Финляндию, Швецию. Сложившиеся в данных культурах стереотипы, безусловно, детерминируют гендерную социализацию их представителей.

Резюмируя вышеизложенное, мы отмечаем, что на гендерную социализацию детей дошкольного возраста влияют такие факторы, как принадлежность к определённой культуре, социальная среда, семья и семейное воспитание, общение с педагогом и сверстниками. Гендерное воспитание следует начинать с дошкольного возраста, так как он является сензитивным и заложенные в данном возрасте духовно-нравственные основы, поведенческие образцы прямым образом влияют на становление и развитие личности в будущем. 


\section{Список литературы:}

1. Гендерный калейдоскоп: курс лекций / под общ. ред. М.М. Малышевой. М.: Academia, 2001. $520 \mathrm{c}$.

2. Быстрай Е.Б., Блессинг Б. Создание природосообразной среды в детском образовательном учреждении 3. Вейгель в Форальберге // Актуальные проблемы дошкольного образования: современные концепции и технологии дошкольного образования: мат-лы XV междунар. науч.-практ. конф. 1617 марта 2017 г., г. Челябинск, Российская Федерация. Челябинск: ЗАО «Цицеро», 2017. С. 74-76.

3. Быстрай Е.Б., Пермякова Н.Е., Артёменко Б.А. [и др.] Теория и технология экологического образования детей дошкольного возраста: монография. Челябинск: изд-во ЗАО «Цицеро», 2017. 222 с.

4. Быстрай Е.Б., Т Тюмасева 3.И., Штыкова Т.В. Ценностные аспекты формирования природолюбия у дошкольников // Современные технологии: актуальные вопросы, достижения и инновации: сб. статей IX междунар. науч.-практ. конф. 27 сентября 2017 г., г. Пенза, Российская Федерация. Пенза: Наука и Просвещение, 2017. С. 152-154.

5. Тюмасева 3.И., Орехова И.Л., Быстрай Е.Б. Приоритеты дошкольного образования: культура, экология и здоровье: монография. Челябинск: Изд-во ЗАО «Цицеро», 2017. 149 с.

6. Батлер Дж. Заметки к перформативной теории собрания. М.: Ад Маргинем Пресс, 2018. 248 с.

7. Быстрай Е.Б., Артёменко Б.А., Власенко О.Н. Виды дошкольных образовательных организаций в Германии // Актуальные проблемы дошкольного образования: современные концепции и технологии дошкольного образования: мат-лы XV междунар. науч.-практ. конф. 16-17 марта 2017 г., г. Челябинск, Российская Федерация. Челябинск: ЗАО «Цицеро», 2017. С. 35-38.

8. Быстрай Е.Б., Зигерист Р.Й. Ретроспективный анализ проблем дошкольного образования в Германии // Актуальные проблемы дошкольного образования: современные концепции и технологии дошкольного образования: мат-лы XV междунар. науч.-практ. конф. 16-17 марта 2017 г., г. Челябинск, Российская
Федерация. Челябинск: ЗАО «Цицеро», 2017. С. 204207.

9. Кон И.С. Сексология. М.: Академия, 2004. $384 \mathrm{c}$.

10. Гусева Ю.Е., Сабунаева М.Л. Гендерные стереотипы: возрастной аспект // Практикум по гендерной психологии. СПб., 2003. С. 153-160.

11. Артёменко Б.А., Гардт С.П. Формирование лидерских качеств у детей дошкольного возраста // Актуальные проблемы дошкольного образования: современные концепции и технологии дошкольного образования: мат-лы XV международной научнопрактической конф. 16-17 марта 2017 г., г. Челябинск, Российская Федерация. Челябинск: ЗАО «Цицеро», 2017. С. 122-124.

12. Быстрай Е.Б., Артёменко Б.А. Роль проектной методики в процессе познавательного развития дошкольников // Культура, наука, образование: проблемы и перспективы: сб. материалов VI междунар. науч.-практ. конф. 13-15 февраля 2017 г., г. Нижневартовск, Российская Федерация. Нижневартовск: НГУ, 2017. С. 33-36.

13. Maccoby E.E., Jacklin C.N. Gender segregation in childhood // Advances in Child Development and Behavior, 1987. Vol. 20. P. 239-287.

14. Maccoby E.E. Gender and relationships: A developmental account // American Psychologist. 1990. 45. P. 513-520.

15. Maccoby E.E. The two sexes: growing up apart. Coming together. L., 1998. P. 118-152.

16. Радина Н.К. К проблеме использования гендерного анализа в психологических исследованиях // Вопросы психологии. 1987. № 4. С. 58-71.

17. Рябов О.В. Матушка-Русь и ее защитники: гендерные аспекты конструирования образа русской интеллигенции в контексте историософских поисков национальной идентичности // Интеллигенция и мир. 2001. № 2/3. C. 75-81.

18. Репина Т.А. Проблемы полоролевой социализации детей. М.: Изд-во МПСИ; Воронеж: Изд-во НПО «МОДЭК», 2004. 288 c.

19. Репина Т.А. Социально-психологическая характеристика группы детского сада. М.: Педагогика, $1988.178 \mathrm{c}$.

\section{FEATURES OF PRESCHOOLERS' GENDER EDUCATION}

(C) 2018

Evtushenko Irina Nikolaevna, candidate of pedagogical sciences, associate professor of Pedagogy and Childhood Psychology Department

Bistray Elena Borisovna, doctor of pedagogical sciences, professor, head of German Language and German Language Teaching Methods Department

Artemenko Boris Alexandrovich, candidate of biological sciences, acting head of Theory, Methods and Management of Preschool Education Department South Ural State Humanitarian Pedagogical University (Chelyabinsk, Russian Federation)

Abstract. The paper emphasizes the importance of gender education of preschool children, determined by changes in the sociocultural background, by shifting the emphasis in people's value orientations. The preschool age is characterized by intense physiological maturation of the body and psyche development. Besides, the child's personality is formed exactly in the preschool age, the potential for successful further life is created. A great role in the gender education of preschoolers is played by socium and norms of social behavior, the value orientations that prevail in it at a given time. In this connection, the system of preschool education faces the problem of assimilating the child's social experience, meaningful for the life in society, and the adoption of the existing system of values. The mediator in the communication of the preschool child and the socium is the teacher of the pre-school educational organization, who must understand that the anatomo-morphological and physiological characteristics of the child of preschool age form only the first level of the hierarchical ladder of adulthood and entry into the society A big role in 
Евтушенко И.Н., Быстрай Е.Б., Артёменко Б.А.

the gender socialization of preschool children is assigned to parents, because in the process of monitoring the behavior of their parents, the child develops certain behavioral stereotypes feminically and masculinely colored. The gender socialization of preschool children is greatly influenced by peers.

Keywords: gender; gender education; gender socialization; preschool education; preschool children; femininity; masculinity; behavioral stereotypes; society; social environment; image of self; self-concept; gender identity.

\section{ТЕОРЕТИЧЕСКОЕ ОБОСНОВАНИЕ ПРОЦЕССА КОГНИТИВНОГО МОДЕЛИРОВАНИЯ ПЕДАГОГИЧЕСКИХ СИТУАЦИЙ}

(C) 2018

Камалеева Алсу Рауфовна, доктор педагогических наук, ведущий научный сотрудник Грузкова Светлана Юрьевна, кандидат технических наук, старший научный сотрудник Институт педагогики, психологии и сочиальных проблем (2. Казань, Российская Федерация)

Аннотащия. Целью статьи является поиск методов повышения эффективности процесса обучения в условиях применения когнитивного подхода в современной отечественной дидактике, направленных на использование индивидуальных особенностей инструментария когнитивной организации каждого обучающегося: интеллект, когнитивные стили, память, внимание и т.д.

В данной статье рассматривается применение методологии когнитивного моделирования педагогических ситуаций. Авторами описывается когнитивное моделирование педагогических ситуаций как процесс, состоящий из шести последовательных и взаимосвязанных этапов.

Первый этап состоит в формулировке цели и соответствующих задач.

Второй этап предусматривает сбор, систематизацию и анализ существующей педагогической ситуации с последующим выделением основных факторов, воздействующих на развитие ситуации, и определением взаимосвязи между ними, т.е. создание когнитивной карты.

Третий этап направлен на построение ориентированного графа, содержательное наполнение которого осуществляется с учетом причинно-следственных цепочек, отражающих систему взаимодействия между субъектами образовательного процесса и формирующих педагогическую теорию с использованием понятий, носящих фундаментальный характер в психологии: сознание, мышление, познание, понимание и т.п.

Четвертый этап предполагает объединение когнитивной карты и ориентированного графа в единую когнитивную модель изучаемой педагогической ситуации.

Пятый этап ориентирован на проверку адекватности когнитивной модели реальной педагогической ситуации, т.е. на ее верификацию.

Последний шестой этап позволяет определить с помощью когнитивной модели возможные варианты развития педагогической ситуации, обнаружить пути и механизмы воздействия на ситуацию.

Ключевые слова: когнитивное моделирование; педагогическая ситуация; когнитивная карта; ориентированный граф; когнитивная модель; образовательный процесс; взаимодействие субъектов; когнитивная организация обучающегося; интеллект; когнитивные стили; память; внимание; сознание; мышление; познание; понимание.

Во второй половине XX века, при решении вопроса, касающегося выбора наиболее верного направления деятельности, а также принятия решения и умения работать в условиях неопределенности, американский исследователь Р. Аксельрод [1] предложил использовать методологию когнитивного моделирования.

Необходимо отметить, что в литературе однозначное толкование понятия «когнитивное моделирование» отсутствует, однако выделяют различные трактовки его дефиниций. Так, А.Н. Дахин считает, что «под когнитивным подходом понимается решение традиционных для данной науки проблем методами, учитывающими когнитивные аспекты, которые включают процессы восприятия, мышления, познания, объяснения и понимания» [2, с. 40]. По мнению Е.К. Корноушенко, технология когнитивного анализа и моделирования должна строиться на основе «познавательно-целевой (когнитивной) структуризации знаний как об объекте, так и внешней для него среды» [3, с. 138]. Однако автором не отмечается четкого разграничения понятий «объект» и «внешняя среда». М.С. Можаров же подчеркивает, что «термин "когнитивность" обозначает, в частно- сти, системные проявления сознательных манипуляций с понятийными структурами различных предметных областей. Данные манипуляции характерны для множества психолого-педагогических исследований, поэтому за термином выстраивается целостный педагогический подход, позволяющий формировать педагогическую теорию на основе базовых категорий изучения человека: сознание, мышление, познание, понимание и т.д.» [4].

Процесс когнитивного моделирования предусматривает исполнение когнитивного анализа, выражающегося в изучении восприятия и познания субъекта.

В современной отечественной педагогике когнитивные теории обучения являются наиболее актуальными в качестве психолого-педагогической интерпретации дидактических систем, которые ориентированы на развитие познавательных способностей субъектов, когда «обучение ведется с опорой на непосредственный опыт обучающихся, его расширение в ходе поисковой, исследовательской деятельности, активного освоения мира» [5].

В соответствии с когнитивной теорией обучение не представляет собой только передачу некоторого 